\title{
Can scientific research answer the 'what' question of mathematics education?
}

\author{
Marja van den Heuvel-Panhuizen ${ }^{\star}$ \\ Freudenthal Institute, Utrecht University, The Netherlands
}

This paper problematizes the issue of how decisions about the content of mathematics education can be made. After starting with two examples where research in mathematics education resulted in different choices on the content of primary school teaching, I explore where and how, in the scientific enterprise within the domain of education, issues of the what of mathematics education are addressed. My conclusion is that, although it is often thought that scientific research cannot resolve issues related to decisions about subject matter content and goals, there is a powerful movement, with its roots in the European tradition, that pleads for the further development of didactics as a scientific discipline.

\section{Introduction}

The underlying context of this paper is the curriculum debate that has been going on since the early $1990 \mathrm{~s}$ in primary and secondary school mathematics education. It started in California (see Becker \& Jacob, 1998) as a reaction to the publication of the Standards by the US National Council of Teachers of Mathematics (NCTM, 1989). Together with a constructivist view on teaching mathematics, including considering students as active and collaborative learners, the Standards also signified a curricular change by advocating real-world connected mathematics and a liberal use of calculators and de-emphasizing traditional algorithms and rote memorization. Presumably elicited by international achievement comparisons, the curriculum debate spread geographically and led to heated discussions all over the world. In other words, for outsiders mathematics may be a school subject with an indisputable content, but for those who are involved in mathematics education it is clearly not.

My intention with this paper is to contribute to this curriculum debate by exploring what input scientific research can offer to informed decision-making on the mathematics that is taught in school. Two experiences prompted me to write this paper. The first one was connected to the worldwide reform of mathematics

${ }^{\star}$ Corresponding author: Freudenthal Institute, Utrecht University, Aidadreef 12, $3561 \mathrm{GE}$ Utrecht, The Netherlands. Email: m.vandenheuvel@fi.uu.nl 
education. Considering what is happening in different countries I became more and more aware that having similar views on mathematics education does not automatically mean that the same choices will be made on content. Developers and researchers with, for instance, a constructivist background who thoroughly agree with each other on what are the best teaching methods, may choose different teaching content; a view on teaching methods, even methods based on shared opinions on mathematics as a school subject, clearly does not define what counts as important mathematical content.

The second experience had to do with the discrepancy that arose when a learningteaching trajectory describing the sequence of mathematics problems children roughly follow in primary school was compared with empirical data on the difficulty level of problems. Both experiences emphatically raised the question of how decisions on the content of mathematics education might be made and what kind of research is needed for this.

After discussing these two experiences below, I review how the 'what' question is dealt with in the educational research literature and investigate whether there are possibilities for making content decisions in a scientific way. In other words, I explore whether there are research methods that generate reliable and valid knowledge to contribute to these decisions.

\section{Experience one: instructional principles are not enough to make decisions about subject matter content}

Although our knowledge about the teaching and learning of mathematics is far from complete, it looks as though we are making more and more progress on the question of how students can learn mathematics (see Schoenfeld, 1994; Wiliam, 2003). ${ }^{1}$ Moreover it seems that the views on the how are growing closer. For instance, Putnam (2003) describes the common assumptions on how children learn mathematics that can be found in the newest USA reform curricula for primary school mathematics education. In contrast with the traditional approach in the USA, according to Putnam (ibid.), these curricula view the teacher as guiding the students through discussions and learning activities and conceptualize the learning of mathematics as building on the students' intuitive understanding, providing the students with settings and problems that are meaningful for them, and proceeding from informal, grounded understanding to more formal knowledge of the symbol systems of mathematics.

These ideas about the didactics of teaching mathematics are also very similar to the principles of Realistic Mathematics Education (RME), which was the Dutch answer to the need to reform the teaching of mathematics. The roots of RME go back to the early 1970s when Freudenthal and his colleagues laid its foundations. Briefly, these principles include taking students' initial understanding as a starting point, providing them with problem situations which they can imagine, scaffolding the learning process via models, and evoking reflection by offering the students opportunities to share their experiences (for a more elaborated overview see Van den 
Heuvel-Panhuizen, 2001a). In the Netherlands, as in the USA, this approach contrasts with the traditional mechanistic way of teaching mathematics in which the students are, for instance, offered fixed solving procedures in which they are to be trained through the use of exercises.

However, contrary to what might have been expected, this agreement on principles in no way assures similarity in mathematics programmes. I became explicitly aware of this once again when I read McClain's (2002) chapter in Goodchild and English's (2002) book on researching mathematics classrooms (see Van den Heuvel-Panhuizen, 2002). The chapter reports on a classroom-teaching experiment carried out by herself and Cobb and his colleagues. This focused on the development of a socio-constructivist instructional sequence for adding and subtracting three-digit numbers.

As McClain describes, the content of the instructional sequence that was investigated in the classroom-teaching experiment was, among other things, based on RME principles. The result was quite remarkable. Although the sequence reflects some important RME principles, I would not call it an RME teaching unit. The narrow focus on algorithms in conjunction with heavy emphasis on place value supported by Unifix cubes is quite different from an RME approach. An example of this approach can be found in the TAL learning-teaching trajectory for whole number calculation (Van den Heuvel-Panhuizen, 2001b; more about TAL is in the section in which the second experience is discussed). Characteristic of this trajectory is the integration of written and mental calculations, an orientation towards numbers instead of digits, and the use of the numberline to support the development of strategies to solve problems such as 265-194. Without judging either approach, and certainly not saying that the second approach is better than the approach that was chosen in the classroom teaching experiment, I am left wondering about the evidence base that motivated this different choice in content.

An explanation for this might be that the socio-constructivist instructional sequence was inspired by the teaching tenets of RME. These tenets, however, do not completely encapsulate the domain-specific education theory of RME. In addition to these teaching principles, RME also implies choices for particular goals and content-in its broadest sense-resulting from 'didactical phenomenological analyses' (as suggested by Freudenthal, 1983). These include the analysis of mathematical concepts from a didactical perspective, while bearing in mind knowledge of the history of mathematics, evidence from students' learning, and using experience from collaboration with teachers, teacher educators, teacher counsellors and textbook writers. Taking this into account it is understandable that the content of instructional sequences based only on the RME principles may differ from the previously described RME approach.

Another thing is that the classroom experiment did not bring new insights that led to a fundamental revision of the conjectured trajectory. The revisions were mainly related to the micro-didactical how-questions (How do the students learn? and How to teach or how to organize an instructional environment to optimize the students' learning?), rather than to the macro-didactical what-questions (What should be the 
learning goals? What content should constitute the programme?). Although this may lead to the inference that questions about content cannot be covered within the scope of classroom teaching experiments, I cannot believe that this is a correct conclusion.

Because the answers to macro-didactical what-questions are significantly informed by didactical phenomenological analyses loaded with experiences and opinions of experts in and out of the school, evidence from classrooms can play an important role in providing answers to such questions. However, to achieve this, it is necessary to include research activities that can inform our macro decisions.

As an example, I want here to draw attention to Treffers' (1987) plea to use problems that can be solved in a variety of ways. Students' work on these problems can bring to light their levels of understanding and arithmetic skills at a particular moment. Apart from the fact that this information is important for taking microdecisions it also guides the macro-decisions. The cross-sectional view of the class (the different levels of understanding of the students in a class at one particular moment) that is produced in this way shows at the same time a longitudinal section of a learning-teaching trajectory or a part of it. The solution strategies of individual students reveal collectively essential elements of the long-term path that students need to travel. What is found in the classroom in the present anticipates what is on the horizon and beyond.

Returning to the purpose of McClain's chapter I think that research activities by which we can expose students' future learning must have a place within the methodology of classroom teaching experiments. They can bring us closer to the heart of the design process where instructional trajectories and sequences come into being.

\section{Experience two: empirical data from tests are not enough to make decisions about subject matter content}

The second experience, in which questions emerged as to the role research plays in content decision making, also has to do with the TAL learning-teaching trajectory on whole number calculation. Before dealing with this experience I will first say a few words about the project in which this trajectory was developed.

\section{The TAL Project}

The aim of the TAL Project is to develop learning-teaching trajectories with intermediate attainment targets for all domains in the primary school mathematics curriculum. The project is funded by the Dutch Ministry of Education and carried out by the Freudenthal Institute and the SLO (the Dutch Institute for Curriculum Development), in collaboration with CED (school advisory center for the city of Rotterdam). TAL is a Dutch abbreviation and stands for Intermediate Goals Annex Learning-Teaching Trajectories. The guiding rationale for working on these trajectories was to get a national consensus on the mathematics curricula and in 
particular more coherence between the programmes at the different age levels. The trajectory descriptions are meant to provide the teachers with a concise overview of how children's mathematical understanding can develop from $\mathrm{K} 1$ and 2 (from four-years-old) through Grade 6 (up to 12-years-old) and of how education can contribute to this development. Although a learning-teaching trajectory puts the learning process in line, it should not be seen as a linear and singular step-by-step regime in which each step is necessarily and inexorably followed by the next one. Instead, in the TAL Project a learning-teaching trajectory is seen as a route with bandwidth. It should do justice to differences in learning processes between individual students and to the different levels at which children achieve competency in particular skills and concepts.

The main purpose of the trajectories is to give the teachers a grip on educational decision-making. Although the description contains many examples of classroom activities it is not meant as a practical recipe book, but as a framervork at a conceptual level. Based on the description of fundamental elements of the mathematical content-that has much common ground with Wittmann's (2004) 'fundamental ideas' in which the epistemological structure of subject matter is best expressed-the teachers can develop a mental educational map that guides their teaching. Having an overview of the process the students go through is very important for working on progress in their understanding. To make adequate decisions about help and hints when selecting new problems, a teacher must have a good idea of the goals, the route that can lead to these goals and the landmarks the students will pass at one stage or another along this route. Without this outline in mind, it is difficult for the teacher to value the students' strategies and to foresee where and when one can anticipate students' understandings and skills that are just coming into view in the distance (see also Streefland, 1985). Without this longitudinal perspective, it becomes very difficult to guide students' learning.

For the development of the TAL learning-teaching trajectories, didactical phenomenological analyses play a crucial role. These analyses reveal what kind of mathematics is worthwhile to learn and which actual phenomena can offer possibilities for developing intended mathematical knowledge and understanding. It is important that one tries to discover how students can contact these phenomena, and how they appear to the students. This means that problems and problem situations that give students opportunities to develop insight into mathematical concepts and strategies must be identified. Therefore a team was formed that covered all kinds of specialisms in primary school mathematics. The TAL team contains members with experience in research and development of mathematics education, assessment, teacher education, teacher advice, and the teaching of mathematics in primary school. The core of the work is formed by the (almost) weekly discussions in the project team, for which input comes from a variety of sources: analyses of textbook series, analyses of research literature, classroom investigations, and extensive consultations of experts in mathematics education. In the following I show what content decisions have been made for the domain of estimation in primary school. 
The content domain of estimation as an example

Although estimation is now widely acknowledged as an important goal of mathematics education, most textbooks lack a framework for learning how to estimate. At most, they contain several problems on estimation, but doing a few estimation problems from time to time is not enough to develop real understanding of how estimation works, and it is certainly not sufficient to develop comprehension of what is 'allowed' and what is not when estimating.

The TAL learning-teaching trajectory offers a first proposal for a pathway the students can take to develop estimation skills (for a more elaborated description see Van den Heuvel-Panhuizen, 2001c). The trajectory is based on the fundamental elements of the domain of estimation that are brought to the fore by the didactical phenomenological analyses carried out by the TAL team. The analysis resulted in the conceptual didactical structure for learning and teaching estimation that is shown in Figure 1.

This structure contains a subdivision into four subdomains with three different learning stages. The arrow indicates the global direction of the trajectory for estimation from Grade 3 through to Grade 6 . The basis of estimation is considered as lying in exploring and rounding off numbers, which is followed by estimating in calculation problems. The latter is differentiated into calculations with given numbers that can be rounded off and calculations with estimated values in problems where the necessary data are incomplete or unavailable.

The distinguishing of three learning stages can be seen as the most basic structure in the learning-teaching trajectory:

- In the informal phase the students can globally determine answers without using the standard rounding off rule.

- In the rule-directed phase the students arrive at the standard rounding off rule for operating with numbers and learn to apply this rule.

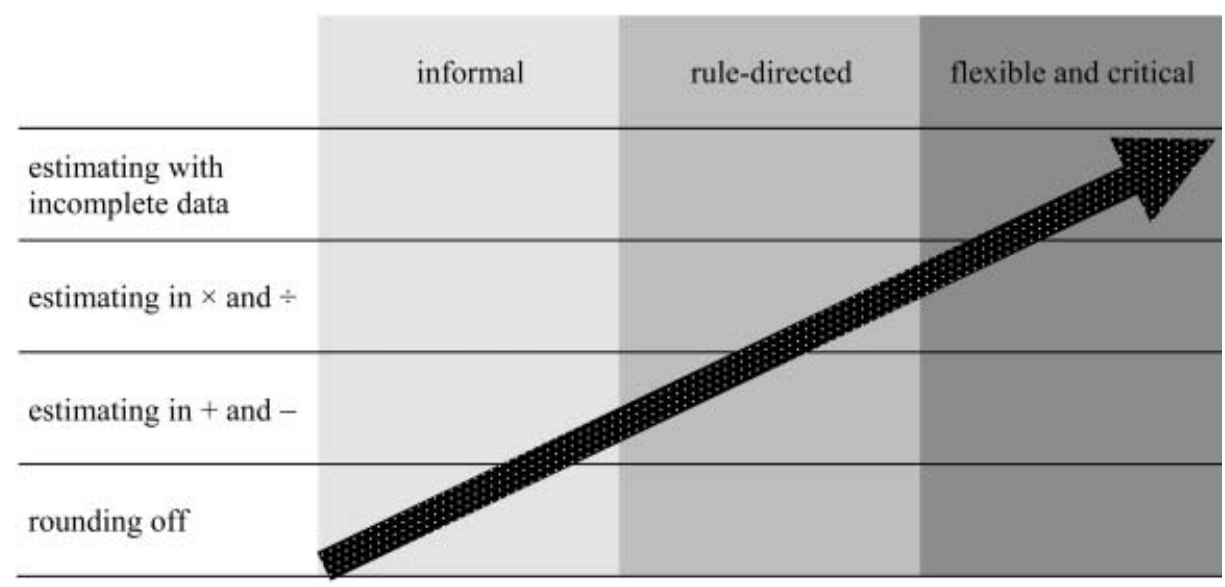

Figure 1. Conceptual didactical structure of the domain of estimation in Grades 3-6. 
- In the flexible and critical phase the students are capable of applying more balanced estimation methods when operating with numbers and they can deal in a critical way with rounded off and exact numbers.

Of the four basic operations, addition and subtraction are offered first. Multiplication and division, however, are more difficult to perceive. This has mainly to do with the fact that in these operations the deviations caused by rounding off become magnified. Therefore it is more difficult to understand the result of a calculation with rounded off numbers and to comprehend the magnitude of the deviation. At this point, learning to estimate is a process that goes beyond primary school. Take, for instance, the following Seats problem (Figure 2).

The A-part of the problem is very easy to answer: $20 \times 30$ would give a close estimate, and at first glance this appears to be a simple estimation problem. The Bpart, however, makes it clear that this problem is actually quite difficult. This is also indicated by Butterworth (1999) who found that this kind of problem, that he called 'false-compensation', is difficult even for university students. Not being aware of this but through our own didactical phenomenological analyses of the domain of estimation we decided to restrict estimation in multiplication and division problems in the learning-teaching trajectory to rule-directed rounding off and to problems in which only one number has to be rounded off. Teachers should be aware that presenting the students with more complex (multiplication and division) estimation problems with numbers that 'automatically' give a good estimate will in fact lead to a type of mock knowledge in the domain of estimation.

\section{Comparison with empirical test data}

Our decision not to include those problems in the primary school trajectory was in contrast with the results from a large-scale study on students' achievements. The large-scale study is the Dutch PPON study carried out every five years by CITO, the Dutch National Institute for Educational Measurement. Figure 3 depicts the empirically established scale of estimation problems for Grade 6 students (12-yearsold) based on the latest mathematics study PPON conducted in 1997 (Janssen et al., 1999). The bars indicate, for estimation problems, the results that were found for students at different levels. Problems such as item one turned out to be easiest, while problems such as item ten were the most difficult. Even the best $10 \%$ of students had an insufficient mastery of this problem, meaning a chance of fewer than $50 \%$ solving it correctly.

\begin{tabular}{|ll|}
\hline A. In the hall, there are 18 rows of 32 seats each. \\
Approximately how many seats altogether?
\end{tabular}

Figure 2. Seats problem. 


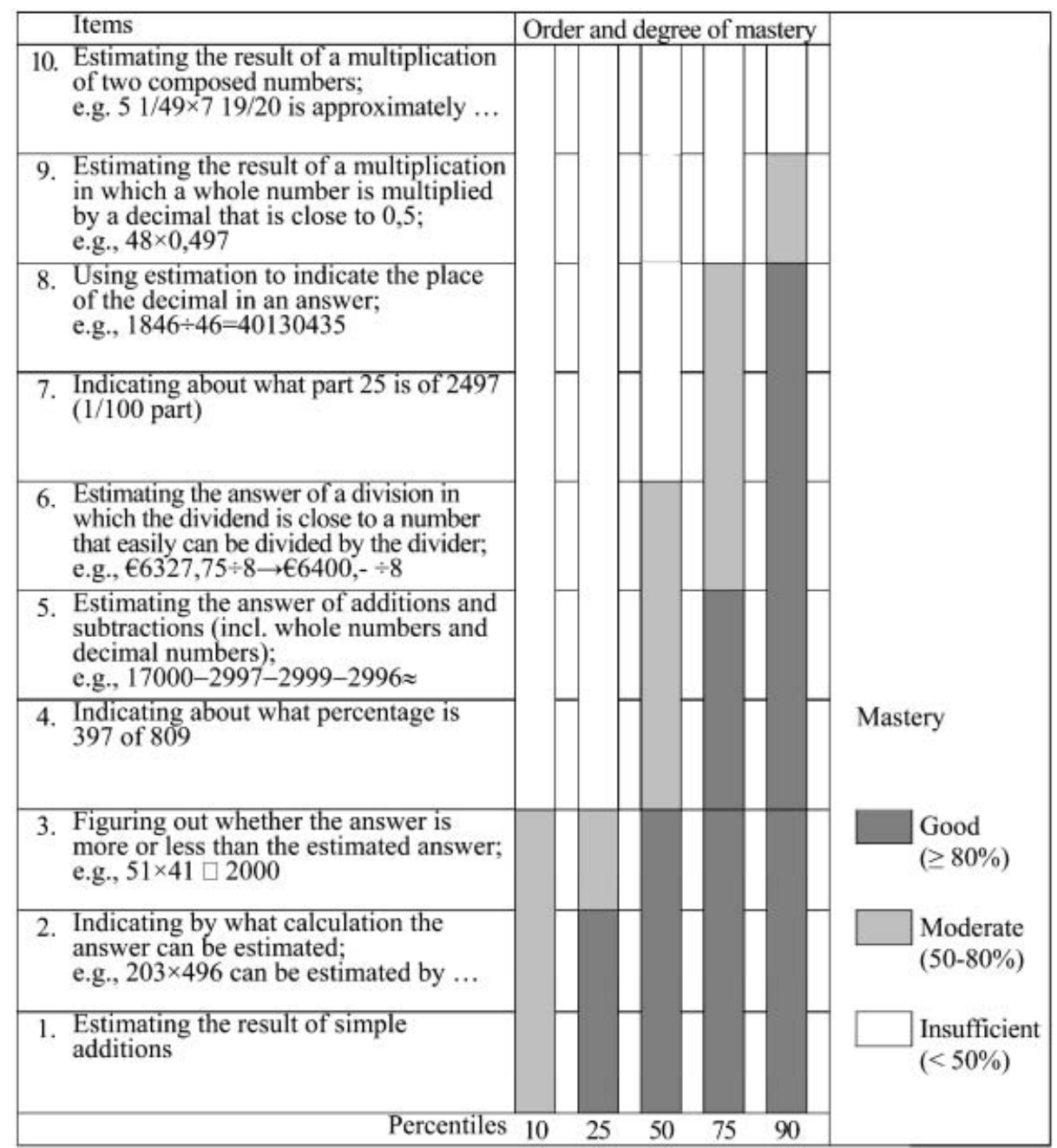

Figure 3. PPON 1997 results on the domain estimation.

A closer look at these results reveals, however, that some problems that are identified here as easy, actually refer to a category of problems that requires a high level of understanding of estimation. This is especially true for items two and three. Similar to the Seats problem, discussed earlier, it is not easy to understand whether $200 \times 500$ gives a larger or a smaller result than the precise answer for $203 \times 496$. In the same way item three belongs to a more difficult category of problem than is indicated here. Changing the numbers a little bit-for instance, changing $51 \times 41$ into $52 \times 38$-would make this problem more difficult.

The above casts some doubt on the usefulness of the previously mentioned empirically determined scale of estimation problems to determine the norm for what is feasible for students in this domain. Therefore such empirical data-even when obtained in an ostensibly unimpeachable and indubitable scientific context-are not 
automatically appropriate for establishing standards and setting up trajectories. So the question of how to take decisions on the what-question of mathematics education still remains open.

\section{Decisions about the 'what'}

Significance attached to the 'what'

The lack of clarity on how decisions about the what of mathematics education can be made, contrasts sharply with the importance that is attached to it. A broad audience, ranging from parents, caregivers, business leaders and politicians to professional educators, cares deeply about what children learn in school (see Senk \& Thompson, 2003). The many countries that formulated standards in the last decade and the interest in international comparative studies such as TIMSS and PISA also reflect this engagement. Although it looks as if this awareness is typical of our present time, this is not the case. Even in 1845, the Secretary of the Massachusetts State Board of Education, Horace Mann, raised the question of whether school was teaching how to calculate the amount of tax that citizens have to pay (see Kilpatrick, 1992).

Just as in Horace Mann's time, the question about the what comes up most significantly within the context of evaluation and assessment. We have to ask very explicitly what knowledge we want students to have (Romberg, 1993). Moreover, we have to ask this question continually. As Romberg and Kaput (1999) make clear, we can no longer assume that mathematics is a fixed body of concepts and skills to be mastered. Mathematics is a living, dynamic discipline, and therefore further changes in school mathematics are inevitable.

\section{What-questions rouse suspicion}

Despite the great concern about what schools are teaching, asking for content specification is often-in one way or another-viewed with some suspicion. For this reason, what-questions are often followed with an explanation that tones down the question and with warnings about the danger of focusing on content. According to Schoenfeld (1994) the danger of the 'content inventory' point of view comes from what it leaves out: the critically important point that mathematical thinking consists of a lot more than knowing facts, theorems, techniques and so forth. In line with him, Burton (2002a) mentions the danger of fragmentation. This danger is also often linked up with the traditional view on subject matter which still holds sway, especially in state guidelines and in textbook specifications (see also Bereiter, 2002). In contrast to the conventional approach of itemizing what is to be learned, the more modern view, associated with labels such as constructivism and conceptual change teaching, looks at subject matter somewhat differently (ibid.). The focus is more on mathematics as a whole and the relationships between the different parts of content. As is shown in the first part of this paper, this focus does not necessarily imply similar content choices-with a result of different learning outcomes. 


\section{Content matters}

There is a wide range of studies showing that 'students learn what they have an opportunity to learn'-as Hiebert (1999, p. 12) says. If extra attention is paid to particular content, then, on average, students learn this content. On the other hand, if a mathematical topic is not taught, then it is often not learned by the students. In other words, different goals and curricula lead to different patterns of achievement (Hiebert, 2003; Kilpatrick, 2003). Again this is not a new finding. The study by Walker and Schafferzick (1974) in which they reviewed a number of curriculum evaluation studies is well known. Similar results were also found in a study carried out in the Netherlands aimed at comparing the achievements of students that had been taught using two different textbooks (Gravemeijer et al., 1993). These findings have important consequences for decisions about the what of mathematics education.

\section{Disagreement about the what}

The problem is that the what is not a unified thing: 'In different countries across the world and within countries themselves, school mathematics looks different' (Lerman, 2004, p. 340). In the USA substantial differences can be found in grade placement of mathematics topics (Senk \& Thompson, 2003) and there is little agreement across the nation on the most appropriate content for any grade level (Lambdin et al., 2004). On an international scale the situation is similar. This is clearly shown by the variation in topics in textbooks found in the TIMSS related study 'According to the book' (Valverde et al., 2002).

The reason for this content difference has to do with making different choices. As stated by Lerman (2004, p. 341), 'to teach in school is always a selection from what we (or whoever decides) perceive to be Mathematics (academic, in business/ industry, etc). Values are always associated with that choice, values as to what education should be all about and in particular what mathematics education should be all about. ... These are political battles ...'

In other words, it might be no surprise that the NCTM Standards sparked a nationwide 'math war' in which positions were taken by mathematicians, mathematics educators, teachers, administrators, parents and politicians (see Becker \& Jacob, 1998; Lambdin et al., 2004). Senk and Thompson (2003) stress that this debate emerged because there is much disagreement about what skills are needed for productive citizenship as well as on whether students can apply their knowledge in everyday life, the workplace, or higher education. According to Hiebert (1999) this lack of consensus is understandable given rapid changes in mathematical competencies that are important in the workplace and the increasing availability of computational technologies.

However, in addition to this, we should not forget that the different agencies that are struggling for what should constitute school mathematics are unlikely to accept that one group dictates what should be 'worthwhile' knowledge (Burton, 2004). Moreover, at the same time it is not very clear who has to decide upon the what. In 
this respect the April 1999 issue of the NCTM discussion journal Mathematics Education Dialogues was very revealing. This issue was completely dedicated to the question 'Who should determine what you teach?' In the editorial introduction it stated that there are different ideas about the level on which decisions about the what should be made. Some people believe that teachers, who are the closest to their students and who know their local situation better than outsiders, should make these choices. Others think that they should be made more centrally, at the school level, the school district level, state or provincial level, national level, or even internationally. By discussing the who-question in this way it looks as if the what of education is a kind of optional up-to-you thing. But is this really the case? This question can be asked in particular when a whole curriculum has to be designed. The macro-decisions that are required for such a design go far beyond the level of the individual teacher-which however does not mean that teachers cannot be involved in making choices of what content is most worthy of being taught.

\section{Claim for research-based decision making}

Notwithstanding projects in which research guided the process of curriculum design, the general feeling exists that in many cases the curricular decisions that have followed depend more on the rhetorical or political power of individuals than on any convincing body of research. Thus, everyone is now asking for research evidence about the relative effectiveness of the new and the traditional approaches to school mathematics' (Lambdin et al., 2004, p. 38).

In my view, this quotation expresses the prevailing interpretation of what research can do: it is seen as a kind of a posteriori research that informs the adequacy of the choices, whilst the process of generating content and goals is situated outside the scientific area. Some would even claim it is not research at all. An example of this interpretation can be found in Kilpatrick et al. (2001). According to them choices about the mathematics curriculum depend in part on what society wants educated adults to know and to be able to do, but these ideas also depend on value judgements based on experiences and convictions, and 'these judgements often fall outside the domain of research. Once the learning objectives for mathematics education have been established, research can guide decisions about how to achieve these objectives' (p.3). In other words, '[research] cannot resolve matters of values and priorities' (Kilpatrick, 2001, p. 424).

Hiebert $(1999,2003)$ has very similar thoughts. According to him research cannot select standards. They are chosen through a complex process that is fed by societal expectations, past practice, research information, and visions of the professionals in the field. Moreover, he stresses that the role that research plays in selecting standards is difficult to pin down. Very helpful in this respect is his distinction between the selecting role and the influencing role of research. His view is that only the latter is possible. He grounds this in the many examples in mathematics education that show that research can influence the nature of standards and the way they are defined. By questioning assumptions, uncovering deficiencies, revealing possibilities, and by 
recreating new needs, research can contribute to these decisions. But again, research evidence must rest on judgements as to what and how much mathematics should be learned, and research cannot set those goals (see also Kilpatrick, 2001).

Despite the conviction that 'curriculum struggles are moral and political, [and] that they cannot be resolved by appealing to "what research shows", (Page, 2001, p. 19), there is a strong claim for research-based decision making. This claim is unambiguously expressed in the report of the Coalition for Evidence-Based Policy (2002), in which the US Department of Education is recommended to base teaching and learning on solid, empirical educational practices. As is said in the title of the report, its aim is to bring evidence-driven progress to education. Therefore the report is calling for a major, department-wide effort to fund studies that randomly assign students to treatment and control groups, to establish what works in educating American children. In other words, it would seem that only the how can be investigated and not the what.

\section{Is there any hope? Can research answer the 'what' question?}

In order to arrive at an answer to the question that guides this paper I now focus on what kind of research might lead us to decisions about the what of mathematics education.

\section{Research can answer this question}

A first answer can be found in Greeno (2003) when he is explaining what kind of research findings can guide the formulation of standards.

First, research can affect standards about the range of possible practices to be
considered. ... Results of research provide information about practices of teaching and
learning, showing how they can be conducted and providing information about possible
outcomes of the practices studied. [Second,] research develops ways of conceptualizing
and understanding activities of learning and teaching, and these conceptualizations and
understandings can be appropriated in discussions and debates about choosing between
alternative practices and evaluating the achievements of schools, teacher, and students.
(2003, pp. 311-312)

Thus research can do more than reveal what is the most effective programme. Support for this broader approach to research can also be found in Hiebert (2003). Despite his statement that research cannot select standards (see the previous section) he mentions explicitly that research in the subject itself can also shape the kinds of standards that are selected. In this way 'transformation' and 'projective geometry' found their way into elementary and secondary curricula and are identified in the NCTM Standards.

And, even for the goals, Hiebert (2003) opens the door further. Although they are based on values and beliefs, several sources of information can address decisions about goals. Hiebert sees two kinds of sources here. One sets the choice of goals in an international context, and the other pertains to whether the goals are overly ambitious. 
The American who goes even further is Bruner. In his contribution to the book Issues in education research (edited by Lagemann \& Shulmann, 1999), he gives an unambiguously affirmative answer to the question of whether goals belong in the field of research: 'Education research, if it is to be effective in the broader society, must extend its concern, as it is now doing, beyond the classroom and beyond pedagogy narrowly defined' (Bruner, 1999, p. 404) and 'education - and education research - cannot be kept separate from the life of the culture at large' (ibid., p. 408). According to Bruner 'the major research question ... is not simply how well our schools and systems of pedagogy teach spelling or mathematics or literacy' but 'the master question from which the mission of education is derived is: what should be taught to whom, and with what pedagogical object in mind?' (ibid., p. 408). The consequence of this is that 'education research ... becomes ... design research in the sense that it explores possible ways in which educational objectives can be formulated and carried out in the light of cultural objectives and values in the broad.' (ibid., p. 408). Bruner is not very explicit on how research might fulfil this task and what will be the implications for the methodology. He only explains:

I am not proposing a technocratic solution to the effect that education research should establish our educational goals as well as help design the methods of achieving them. Rather, the proposal is that modern societies are sufficiently complex so that even the task of setting the goals of education requires careful research as to what be needed in order to achieve such goals as may be set. (ibid., p. 408)

Furthermore, he emphasizes that we need 'much better knowledge about the role of education and schooling in shaping the ways of the society' (ibid., p. 408).

Although in the USA Bruner's view on research is rather unusual, this is not the case for researchers in Europe. For Burton (2002b, p. 8), for instance, it is obvious that 'as researchers in the field of mathematics education, we are part of a social science in which we are researching aspects of human experience. Such experience is embedded in social and cultural contexts that cannot be ignored whether the researcher shares, or is alien to, those contexts.'

\section{Specific methodology and epistemology are needed}

In addition to this, Burton (2002b) makes it clear that this might imply that - in order to cope with the problems of the discipline-we might need to construct a specific methodology:

The history of research in the discipline of mathematics education is that it has, until recently, followed the well-worn paths of psychology and sociology as they apply to education. Inevitably, this has led to methodology being treated as the unproblematic statement of the methods used in the research [and that this] must be reassessed. (Burton, 2002b, p. 9)

Although coming from another field of work the following quotation is very meaningful in this respect: "The "normal" way of creating "truth" must not be allowed to persist and dominate research where corroborative evidence is impossible' 
(Herbert, 1989, quoted by Burton, 2002b, p. 7). Later, Burton (2002b, p. 9) clarifies that this need for a different methodology has to do with a different epistemology:

Often, the epistemology held about mathematics can be in conflict with the social science approach to behaviour preferred by the researcher. This is a particular problem for those researching in mathematics education. We have been educated to believe in the 'objectivity' of mathematics; at the same time, we might be trying to hold a belief in learning being socially negotiated. Thus we might end up with internally contradictory stances. (Burton, 2002b, p. 8)

Burton is not a single voice in the wilderness. Bereiter (2002) came to a comparable judgement - although he has a different interpretation of epistemology. According to him educators are pressed for conformity to a pedagogical philosophy because of the absence of an epistemology adequate to deal with subject matter. $\mathrm{He}$ mentions the example of number sense that now appears regularly in curriculum standards and which needs more conceptualization:

Reformers ... need concepts that allow them to think constructively about issues like the following: Why something is worth learning-apart from its conjectured long-term utility in the job market and apart from its traditional backing; why, in other words, a student might feel disposed to learn it. ... Answering questions like these requires getting deeply into subject matter and into the cognitive developmental and instructional research in various domains. (Bereiter, 2002, p. 432)

To me, these remarks sound very familiar. Thinking about the subject matter in order to find out what is the mathematics that is worthwhile to teach, is what Freudenthal $(1978,1983)$ emphasized. This is something which still has a great influence on our work in the Netherlands and which can also be recognized in our Utrecht colleagues' work in the field of science education. See, for example, the work of Lijnse (2002) who pleads for a thorough didactical, conceptual analysis of the subject matter content that is taught in science, in order to come to didactical structures that can both be considered as a basis for teaching trajectories and as a particular way of formulating didactical theory. According to him such an analysis is lacking in the mainstream of science education research.

Of course this focus on content from the point of view of subject matter is not just our local concern. It is an approach that is rooted in a European tradition. Exemplary in this context is Wittmann's work. He advocates mathematics education as a design science (see Wittmann, 1998, 2004) focused on the design of substantial learning environments of which "[the] "substance" derives mainly from the epistemological richness of the subject matter ... whereby "richness" also includes the problems to be explored by the students' (2004, p. 114). To bring this richness in mathematics teaching to the surface, analyses of elementary mathematics from the mathematical point of view have to go together with analyses of curricular traditions, applications of mathematics in various fields, the history of elementary mathematics, the psychology of mathematical thinking and experiences in the classroom. As early as the 1990s, Wittmann was pleading for a redefinition of the basic orientation for research: 'didactic research and development in general get their specific orientation from the requirements of the core' (Wittmann, 1992, p. 4) and 'work in the core 
must start from mathematical activity' (ibid., p. 5). In Wittmann's view research and development in mathematics education includes a variety of components, such as (1) 'development of local theories, for example, on mathematizing, problem solving, proof, practising skills'; (2) 'mathematical analysis of content and the identification of possible contents of mathematics teaching focused at making them accessible for learners'; (3) 'critical examination and justification of contents in view of general goals of mathematics teaching' (ibid., p.2).

In the same paper Wittmann also touched upon the sometimes denied scientific status of the activities connected to the core, but in his eyes, borrowing standards from, for instance, psychology is no option. ${ }^{2}$ 'The establishment of scientific standards in mathematics education by taking over of the standards from the related disciplines leads ... to the unacceptable result that problems and tasks of mathematics education are tackled only insofar and to the extent as they are accessible to the methods of the related disciplines, and that the core is not sufficiently recognized as a scientific field of its own' (ibid., p. 6).

\section{Didactics as a scientific discipline}

In Europe, the scientific discipline related to the research and development of mathematics education is called the 'didactics of mathematics' (Wittmann, 1984; Biehler et al., 1994; Kansanen, 1995; Bengtsson, 1997; Brousseau et al., 1997). In the introductory chapter of Biehler et al's book Didactics of mathematics as a discipline, Winkelmann (1994, p. 11) describes this discipline as follows:

In didactics of mathematics as a scientific discipline, [the] art [of elementarization; that includes the choosing, preparing and evaluating mathematical topics for teaching purposes] and, furthermore, the whole process of reorganizing mathematical knowledge for the purpose of schools and teaching are described and methodologically reflected.

The three problem fields distinguished by Niss (1994) can be considered as the guiding questions for this discipline. According to him the process of preparing mathematics for students includes the 'problem of justification' (why to teach particular parts of mathematics?); the 'problem of possibility' (can these be taught, and if so, how?); the 'problem of implementation' (how to make the teaching possible?).

However, the role that mathematics - as a subject matter domain and as a human activity - is assumed to play in answering these questions varies. As Winkelmann (1994, p. 11) explains:

... there are different traditions in different cultures and different didactical schools of handling this process of choosing, preparing and evaluating mathematical topics for teaching purposes. These traditions differ in their emphasis on specific elementarization strategies, students' needs, fundamental ideas of mathematics, topic levels (examples, concepts, methods, or general ideas such as model building), description levels and the like, and degrees of elaboratedness.

For instance, as a result of a negotiation process in which mathematics education researchers, mathematicians, psychologists, and classroom teachers as well as 
politicians, supervisors, and the lay public are involved, elementarization is considered as an interdisciplinary enterprise in the North American tradition. This view contrasts, for instance, with the approach in Germany and Austria where the community of mathematics educators is coping with problems of defining and justifying mathematical curricula and the underlying goals.

Kansanen (1995) wrote a very interesting paper on the difference between German didactics and American research on teaching. He points to the difference in historical background: 'By nature, the "Didaktik" in Germany has always been philosophical thinking, theorizing, and construction of theoretical models' while in the USA 'the fundamental interest in teaching was practical by nature' and 'most of the research on teaching has been empirical and with quantitative methods' (ibid., pp. 2-3). According to him, within the German 'erudition-centred didactics'-that has a close connection to subject matter didactics that in German is called 'Fachdidaktik' - the content of education is selected according to its value in the curriculum and the instructional process. In other words, this approach claims to have educational autonomy and expert knowledge in educational matters. Moreover, 'in this system there are both formal educational criteria and clear normative decisions' (ibid., pp. 12-13)

Indeed, within the European tradition it is widely recognized that didactics has both normative and descriptive aspects (Imsen, 1999). Because 'no teaching is possible without choices concerning goals, content and methods ... it doesn't seem plausible to leave the questions of norms and values outside the discipline of didactics' (Bengtsson, 1997, p. 2). As discussed earlier, this is in contrast with the perception that many American researchers of mathematics education have that including values imposes a threat to the scientific quality of their work. This narrow interpretation of what it means to be 'scientific' implies that questions about the what can only be answered outside the 'scientific' discipline and that 'scientific' activity is restricted to monitoring the process of negotiation with all interest groups by 'scientific' survey methods. I believe that such an a posteriori approach does not offer us enough possibilities for further development of the practice and the theory of mathematics education. Instead of putting decision-making about the content and goals outside of mathematics education research, I believe that it should be at its heart.

\section{Notes on contributor}

Marja van den Heuvel-Panhuizen is a senior researcher at the Freudenthal Institute (Utrecht University, the Netherlands) and in the winter term, 2004-2005, was a visiting professor at the University of Dortmund, Germany. Her research interests lie with instruction theory for mathematics education, curriculum development and professional development, largely in the area of primary school mathematics. Within this field she has a leading role in developing assessments of students' achievements in mathematics. Another topic of her research activities is gender differences in mathematics education. She has worked on a number of national and international research projects, including comparative and evaluative studies, and design research. 


\section{Notes}

1. While contrasting 'what' and 'how', I am aware that it is almost impossible to separate these concepts. They cohere. Teaching methods determine what can be learned; and the choice for particular content has consequences for the teaching methods as well. Furthermore, in a curriculum (part of) the content can also be expressed by means of the how, namely by describing the learning environment the teacher has to offer.

2. Although Wittmann (1992) admits that mathematics educators by retreating into a 'mathematical garden' may have trivialized the educational aspects of mathematics education and, as a result, those working in the areas of psychology and pedagogy may have neglected the mathematical aspects, he regrets greatly that the related disciplines are arguing against the scientific status of didactics. According to him, this leads to an unreasonable set back into reductionist positions that were analyzed as unfounded many years ago.

\section{References}

Coalition for Evidence-Based Policy (2002) Bringing evidence-driven progress to education: A recommended strategy for the US Department of Education (Washington, DC, US Department of Education).

Becker, J. P. \& Jacob, B. (1998) Math war development in the United States (California), ICMI Bulletin, 44 (June), 16-25.

Bengtsson, J. (1997) Didactical dimensions. Possibilities and limits of an integrated didactics, Fournal of Swedish Educational Research, 2(4), 241-261.

Bereiter, C. (2002) Education and mind in the knowledge age (Mahwah, NJ, Lawrence Erlbaum Associates).

Biehler, R., Scholz, R. W., Strässer, R. \& Winkelmann, B. (Eds) (1994) Didactics of mathematics as a scientific discipline (Dordrecht, Kluwer Academic Publishers).

Brousseau, G., Balacheff, N., Cooper, M., Sutherland, R. \& Warfield, V. (1997) Theory of didactical situations in mathematics: didactique des mathématiques, 1970-1990 (Dordrecht, Kluwer Academic Publishers).

Bruner, J. (1999) Some reflections on education research, in: E. C. Lagemann \& L. S. Shulman (Eds) Issues in education research: problems and possibilities (San Francisco, CA, Jossey-Bass), 399-409.

Burton, L. (2002a) Recognizing commonalities and reconciling differences in mathematics education, Educational Studies in Mathematics, 50, 157-175.

Burton, L. (2002b) Methodology and methods in mathematics education research: where is 'the why'?, in: S. Goodchild \& L. English (Eds) Researching mathematics classrooms: a critical examination of methodology (London, Praeger), 1-10.

Burton, L. (2004) Learning as research, in: B. Clarke, D. M. Clarke, G. Emanuelsson, B. Johansson, D. V. Lambdin, F. K. Lester, A. Wallby \& K. Wallby (Eds) International perspectives on learning and teaching mathematics (Göteborg, National Center for Mathematics Education), 283-297.

Butterworth, B. (1999) The mathematical brain (London, Macmillan).

Freudenthal, H. (1978) Weeding and sowing. Preface to a science of mathematical education (Dordrecht, Reidel Publishing Company).

Freudenthal, H. (1983) Didactical phenomenology of mathematical structures (Dordrecht, Reidel Publishing Company).

Goodchild, S. \& English, L. (Eds) (2002) Researching mathematics classrooms: a critical examination of methodology (London, Praeger).

Gravemeijer, K., Van den Heuvel-Panhuizen, M., Van Donselaar, G., Ruesink, N., Streefland, L., Vermeulen, W., Te Woerd, E. \& Van der Ploeg, D. (1993) Methoden in het rekenwiskundeonderwijs, een rijke context voor vergelijkend onderzoek (Utrecht, CD-B Press). 
Greeno, (2003) Situative research relevant to standards for school mathematics, in: J. Kilpatrick, W. G. Martin \& D. Schifter (Eds) A research companion to principles and standards for school mathematics (Reston, VA, NCTM), 304-332.

Herbert, C. (1989) Talking of silence (London, Falmer Press).

Hiebert, J. (1999) Relationships between research and the NCTM Standards, fournal for Research in Mathematics Education, 30(1), 3-19.

Hiebert, J. (2003) What research says about the NCTM Standards, in: J. Kilpatrick, W. G. Martin $\&$ D. Schifter (Eds) A research companion to principles and standards for school mathematics (Reston, VA, NCTM), 5-23.

Imsen, G. (1999) Reflection as a bridging concept between normative and descriptive approaches to didactics, in: B. Hudson, F. Buchberger, P. Kansanen \& H. Seel (Eds) Didaktik/ fachdidaktik as science(-s) of the teaching profession? (Sweden, Department of Teacher Education and Research, Umea University), 95-105.

Janssen, J., van der Schoot, F., Hemker, B. \& Verhelst, N. (1999) Balans van het rekenwiskundeonderwijs aan het einde van de basisschool 3 (Arnhem, Cito).

Kansanen, P. (1995) The Deutsche Didaktik and the American research on teaching, in: P. Kansanen (Ed.) Discussions on some educational issues VI (University of Helsinki, Department of Teacher Education), 92-118.

Kilpatrick, J. (1992) A history of research in mathematics education, in: D. A. Grouws (Ed.) Handbook of research on mathematics teaching (New York, NCTM/Macmillan), 3-38.

Kilpatrick, J. (2001) Where is the evidence?, fournal for Research in Mathematics Education, 32(4), 421-427.

Kilpatrick, J. (2003) What works?, in: S. L. Senk \& D. R. Thompson (Eds) Standards-based school mathematics curricula. What are they? What do students learn? (Mahwah, NJ, Lawrence Erlbaum Associates), 161-178.

Kilpatrick, J., Swafford, J. \& Findell, B. (Eds) (2001) Adding it up: helping children learn mathematics (Washington, DC, National Academy Press).

Lagemann, E. C. \& Shulman, L. S. (Eds) (1999) Issues in education research: problems and possibilities (San Francisco, CA, Jossey-Bass), 299-335.

Lambdin, D. V., Essex, N. K. \& Kehle, P. E. (2004) What are American elementary students learning?, in: B. Clarke, D. M. Clarke, G. Emanuelsson, B. Johansson, D. V. Lambdin, F. K. Lester, A. Wallby \& K. Wallby (Eds) International perspectives on learning and teaching mathematics (Göteborg, National Center for Mathematics Education), 37-50.

Lerman, (2004) Learning how to be in the mathematics classroom, in: B. Clarke, D. M. Clarke, G. Emanuelsson, B. Johansson, D. V. Lambdin, F. K. Lester, A. Wallby \& K. Wallby (Eds) International perspectives on learning and teaching mathematics (Göteborg, National Center for Mathematics Education), 339-350.

Lijnse, P. (2002) Op weg naar een didactische sctructuur van de natuurkunde? De ontwikkeling van didactische structuren volgens een probleemstellende benadering, Tijdschrift voor Didactiek der $\beta$-wetenschappen, 19(2), 62-92.

McClain, K. (2002) A methodology of classroom teaching experiments, in: S. Goodchild \& L. English (Eds) Researching mathematics classrooms: a critical examination of methodology (London, Praeger), 91-111.

National Council of Teachers of Mathematics (1989) Curriculum and evaluation standards for school mathematics (Reston, VA, NCTM).

Niss, M. (1994) Mathematics in society, in: R. Biehler, R. W. Scholz, R. Strässer \& B. Winkelmann (Eds) Didactics of mathematics as a scientific discipline (Dordrecht, Kluwer Academic Publishers), 367-378.

Page, R. N. (2001) Reshaping graduate preparation in educational research methods: one school's experience, Educational Researcher, 30(5), 19-25. 
Putnam, R. T. (2003) Commentary on four elementary mathematics curricula, in: S. L. Senk \& D. R. Thompson (Eds) Standards-based school mathematics curricula. What are they? What do students learn? (Mahwah, NJ, Lawrence Erlbaum Associates), 161-178.

Romberg, T. A. (1993) How one comes to know: models and theories of the learning of mathematics, in: M. Niss (Ed.) Investigations into assessment in mathematics education. An ICMI study (Dordrecht, Kluwer Academic Publishers), 97-111.

Romberg, T. A. \& Kaput, J. J. (1999) Mathematics worth teaching, mathematics worth understanding, in: E. Fennema \& T. A. Romberg (Eds) Mathematics classrooms that promote understanding (Mahwah, NJ, Lawrence Erlbaum Associates), 3-17.

Schoenfeld, A. H. (1994) What do we know about mathematics curricula?, fournal of Mathematical Behaviour, 13(1), 55-80.

Senk, S. L. \& Thompson, D. R. (Eds) (2003) Standards-based school mathematics curricula. What are they? What do students learn? (Mahwah, NJ, Lawrence Erlbaum Associates).

Streefland, L. (1985) Vorgreifendes Lernen zum Steuern Langfristiger Lernprozesse, in: W. Dörfler \& R. Fischer (Eds) Empirische Untersuchungen zum Lehren und Lernen von Mathematik. Beiträge zum 4. Internationalen Symposium für Didaktik der Mathematik in Klagenfurt in 1984 (Wien, Hölder-Pichler-Tempsky), 271-285.

Treffers, A. (1987) Three dimensions. A model of goal and theory description in mathematics instruction - the Wiskobas Project (Dordrecht, Reidel Publishing Company).

Valverde, G. A., Bianchi, L. J., Wolfe, R. G., Schmidt, W. H. \& Houang, R. T. (2002) According to the book. Using TIMSS to investigate the translation of policy into practice through the world of textbooks (Dordrecht, Kluwer Academic Publishers).

Van den Heuvel-Panhuizen, M. (2001a) Realistic mathematics education in the Netherlands, in: J. Anghileri (Ed.) Principles and practices in arithmetic teaching. Innovative approaches for primary classroom (Buckingham, Open University Press), 49-63.

Van den Heuvel-Panhuizen, M. (Ed.) (2001b) Children learn mathematics (Utrecht/Enschede, Freudenthal Institute, Utrecht University/SLO).

Van den Heuvel-Panhuizen, M. (2001c) Estimation, in: M. van den Heuvel-Panhuizen (Ed.) Children learn mathematics (Utrecht/Enschede, Freudenthal Institute, Utrecht University/ SLO), 173-202.

Van den Heuvel-Panhuizen, M. (2002) Towards scientific research in classrooms? in: S. Goodchild \& L. English (Eds) Researching mathematics classrooms: a critical examination of methodology (London, Praeger), 111-115.

Walker, D. F. \& Schafferzick, J. (1974) Comparing curricula, Review of Educational Research, $44(1), 83-111$.

Wiliam, D. (2003) The impact of educational research on mathematics education, in: A. J. Bishop, M. A. Clements, C. Keitel, J. Kilpatrick \& F. K. S. Leung (Eds) Second international handbook of mathematics education (Dordrecht, Kluwer Academic Publishers), 471-490.

Winkelmann, B. (1994) Preparing mathematics for students, in: R. Biehler, R. W. Scholz, R. Strässer \& B. Winkelmann (Eds) Didactics of mathematics as a scientific discipline (Dordrecht, Kluwer Academic Publishers), 9-13.

Wittmann, E. (1984) Teaching units as the integrating core of mathematics education, Educational Studies in Mathematics, 15, 25-36.

Wittmann, E. (1992) Quo vadis, mathematics education?, fournal für Mathematikdidaktik, 13(1), 55-70.

Wittmann, E. (1998) Mathematics education as a 'design science', in: A. Sierpinska \& J. Kilpatrick (Eds) Mathematics education as a research domain: a search for identity. An ICMI study. Book 1 (Dordrecht, Kluwer Academic Publishers), 87-103.

Wittmann, E. (2004) Assessing preschoolers' geometric knowledge, in: B. Clarke, D. M. Clarke, G. Emanuelsson, B. Johansson, D. V. Lambdin, F. K. Lester, A. Wallby \& K. Wallby (Eds) International perspectives on learning and teaching mathematics (Göteborg, National Center for Mathematics Education), 113-126. 